\title{
Multisystem inflammatory syndrome in children in Canada
}

\author{
Meghan Laverty ${ }^{1}$, Marina Salvadori', Susan G Squires ${ }^{1}$, May Ahmed ${ }^{2}$, Lisa Eisenbeis ${ }^{3}$, Santina Lee ${ }^{4}$, \\ Annick Des Cormiers ${ }^{5}$, Y Anita Li ${ }^{1 *}$
}

\begin{abstract}
This article provides a summary of the epidemiology of multisystem inflammatory syndrome in children (MIS-C) cases reported nationally in Canada by provincial and territorial health authorities. Multisystem inflammatory syndrome in children is a post-viral inflammatory syndrome that temporally follows coronavirus disease 2019 (COVID-19). Symptoms may include fever, abdominal pain, vomiting, diarrhea, skin rash and other signs of inflammation. In Canada, MIS-C is rare, with 269 cases reported to the Public Health Agency of Canada between March 11, 2020 and October 2, 2021. One hundred forty-two (53\%) of these cases were lab-confirmed COVID-19 cases or epidemiologically-linked with COVID-19 cases. Cases have been reported in infants as young as one week to youth as old as 18 years, with a median age of six years. Cases were more likely to occur in males than females ( $58 \%$ vs $42 \%$, respectively; $p=0.006$ ). Almost all MIS-C cases (99\%) required hospitalization and $36 \%$ required intensive care unit admission. No deaths have been reported to date. The time trend of MIS-C aligns with the incidence rate time trend of COVID-19 reported in children, with a two to six-week lag.
\end{abstract}

Suggested citation: Laverty M, Salvadori MI, Squires SG, Ahmed MA, Eisenbeis L, Lee SJ, Des Cormiers A, Li YA. Multisystem inflammatory syndrome in children in Canada. Can Commun Dis Rep 2021;47(11):461-5.

https://doi.org/10.14745/ccdr.v47i11a03

Keywords: inflammatory syndrome, COVID-19, children's health, surveillance, MIS-C

\section{Introduction}

Since the emergence of the novel severe acute respiratory syndrome coronavirus 2 (SARS-CoV-2) that causes coronavirus disease 2019 (COVID-19), data on children and youth aged 19 years and younger infected with SARS-CoV-2 indicate that they usually experience mild disease with less severe outcomes compared with adults. However, on April 26, 2020, clinicians in the United Kingdom reported an increase in accounts of previously healthy children presenting with a severe inflammatory syndrome with features similar to toxic shock syndrome and incomplete Kawasaki disease (1). These cases occurred in children who tested positive for recent or current infection with SARS-CoV-2 or who had an epidemiological link to a COVID-19 case (1). Since then, additional cases of children presenting with a severe inflammatory syndrome with evidence of COVID-19 infection have been reported worldwide. This illness has been labelled multisystem inflammatory syndrome in children (MIS-C) by the Centers for Disease Control and Prevention and the World Health Organization (WHO), and is defined by the WHO as follows (2):

Children and adolescents 0-19 years of age with fever for three or more days

\section{AND}

Two of the following:

- Hypotension or shock (NT-proBNP) abdominal pain)

AND

AND
This work is licensed under a Creative Commons Attribution 4.0 International License.

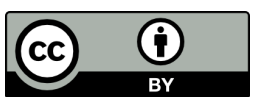

Affiliations

${ }^{1}$ Centre for Immunization and Respiratory Infectious Diseases, Public Health Agency of Canada, Ottawa, ON

${ }^{2}$ BC Centre for Disease Control, Vancouver, BC

${ }^{3}$ Alberta Health Services, Edmonton, $A B$

${ }^{4}$ Communicable Disease Control, Public Health, Manitoba Health, Winnipeg, MB

${ }^{5}$ Ministère de la Santé et des Services sociaux, Québec, QC

*Correspondence:

yanita.li@phac-aspc.gc.ca

- Rash or bilateral non-purulent conjunctivitis or mucocutaneous inflammation signs (oral, hands or feet)

- Features of myocardial dysfunction, pericarditis, valvulitis, or coronary abnormalities (including ECHO findings or elevated troponin/ $\mathrm{N}$-terminal pro-brain natriuretic peptide

- Evidence of coagulopathy (by prothrombin time, partial thromboplastin time, elevated D-dimer)

- Acute gastrointestinal problems (diarrhea, vomiting or

Elevated markers of inflammation such as C-reactive protein, erythrocyte sedimentation rate or procalcitonin

No other obvious microbial cause of inflammation, including bacterial sepsis, staphylococcal or streptococcal shock syndromes 
AND

Evidence of COVID-19 (reverse transcription polymerase chain reaction; RT-PCR, antigen test or serology positive) or likely contact with patients with COVID-19.

Canada expanded this case definition to include cases that met the WHO criteria for MIS-C, with and without COVID-19 diagnosis. This was done to capture possible cases that may have had RT-PCR testing too late in their course of infection (false negatives), and those who, more commonly in the early stages of the pandemic, may not have had access to COVID-19 testing or serology testing (3).

The Public Health Agency of Canada began collecting data on June 30, 2020 on cases of MIS-C dating back to March 11, 2020, when the pandemic was first declared. This report presents cases with illness onset from March 11, 2020 to October 2, 2021 (epidemiological week 11 of 2020 to week 39 of 2021).

\section{Current situation}

A total of 269 cases of MIS-C were reported to the Public Health Agency of Canada during the surveillance period. Data from March 11, 2020 to May 31, 2021 were available from 12 of 13 provinces and territories (PTs), of which,

11 reported lab-confirmed, epi-linked and non-COVID-19-related cases and one reported lab-confirmed cases only. Data were available from 11 PTs for the rest of surveillance period. Of the 269 cases, 127 (47\%) tested positive for COVID-19 via RT-PCR, antigen test or serology and an additional 15 (6\%) were epidemiologically-linked to a lab-confirmed COVID-19 case. The remaining 127 (47\%) either tested negative or were not tested for COVID-19. Details on the COVID-19 testing conducted for each case were not available. The proportion of MIS-C cases among confirmed COVID-19 cases in children aged 19 years and younger was $0.039 \%$ in Canada during the surveillance period.

The characteristics of MIS-C cases reported in Canada are summarized in Table 1. The median age was six years old (range one week to 18 years), with $58 \%$ of cases in children ages five years and older. When cases are restricted to those with a positive COVID-19 test or epidemiological link to a confirmed case of COVID-19, the median age is eight years old (range one week to 18 years), with $70 \%$ of cases aged five years or older. This differs from Kawasaki disease, which primarily affects children younger than five years of age (4). Multisystem inflammatory syndrome in children was more likely to occur in males than females $(p=0.006)$, with over half $(58 \%)$ of reported cases in males. Nearly all (99\%) of MIS-C cases required hospitalization, with $36 \%$ requiring intensive care unit admission. Where outcome information was available, the majority of cases had recovered. The remaining cases were either convalescing or stable at the time of the most recent case report update. No deaths were reported to date.

To date, the number of cases of MIS-C reported in Canada were highest from December 2020 to early March 2021. This followed a peak in the incidence of COVID-19 reported in children and

Table 1: Characteristics of reported cases of multisystem inflammatory syndrome in children according to SARS-CoV-2 ${ }^{\text {a }}$ infection status, Canada, March 11, 2020 to October 2, 2021

\begin{tabular}{|c|c|c|c|c|c|c|c|c|}
\hline \multirow[t]{2}{*}{ Characteristic } & \multicolumn{2}{|c|}{$\begin{array}{l}\text { Lab-confirmed only } \\
\qquad(n=127)\end{array}$} & \multicolumn{2}{|c|}{$\begin{array}{l}\text { Lab-confirmed and/or } \\
\text { epidemiological link } \\
\qquad(n=142)\end{array}$} & \multicolumn{2}{|c|}{$\begin{array}{c}\text { No known evidence of } \\
\text { SARS-CoV-2 infection or } \\
\text { exposure } \\
(n=127)\end{array}$} & \multicolumn{2}{|c|}{$\begin{array}{c}\text { All patients } \\
(n=269)\end{array}$} \\
\hline & $\mathbf{n}$ & $\%^{b}$ & $\mathbf{n}$ & $\%$ & $\mathbf{n}$ & $\%$ & $\mathbf{n}$ & $\%$ \\
\hline \multicolumn{9}{|l|}{ Sex } \\
\hline Male & 82 & 65 & 92 & 65 & 65 & 51 & 157 & 58 \\
\hline Female & 45 & 35 & 50 & 35 & 62 & 49 & 112 & 42 \\
\hline \multicolumn{9}{|c|}{ Age category (years) } \\
\hline Younger than 1 & 1 & 1 & 1 & 1 & 15 & 12 & 16 & 6 \\
\hline $1-4$ & 36 & 28 & 41 & 29 & 55 & 43 & 96 & 36 \\
\hline $5-9$ & 46 & 36 & 51 & 36 & 30 & 24 & 81 & 30 \\
\hline $10-14$ & 30 & 24 & 34 & 24 & 15 & 12 & 49 & 18 \\
\hline $15-19$ & 14 & 11 & 15 & 11 & 12 & 9 & 27 & 10 \\
\hline \multicolumn{9}{|l|}{ Range } \\
\hline $\begin{array}{l}\text { Median age } \\
\text { (range in years) }\end{array}$ & & $8(0-18)$ & & $8(0-18)$ & & $4(0-17)$ & & $6(0-18)$ \\
\hline \multicolumn{9}{|l|}{ Hospitalized ${ }^{\mathrm{c}}$} \\
\hline Yes & 127 & 100 & 142 & 100 & 125 & 98 & 267 & 99 \\
\hline No & 0 & 0 & 0 & 0 & 2 & 2 & 2 & 1 \\
\hline
\end{tabular}


Table 1: Characteristics of reported cases of multisystem inflammatory syndrome in children according to SARS-CoV-2ª infection status, Canada, March 11, 2020 to October 2, 2021 (continued)

\begin{tabular}{|c|c|c|c|c|c|c|c|c|}
\hline \multirow[t]{2}{*}{ Characteristic } & \multicolumn{2}{|c|}{$\begin{array}{l}\text { Lab-confirmed only } \\
\qquad(n=127)\end{array}$} & \multicolumn{2}{|c|}{$\begin{array}{l}\text { Lab-confirmed and/or } \\
\text { epidemiological link } \\
\qquad(n=142)\end{array}$} & \multicolumn{2}{|c|}{$\begin{array}{c}\text { No known evidence of } \\
\text { SARS-CoV-2 infection or } \\
\text { exposure } \\
(n=127)\end{array}$} & \multicolumn{2}{|c|}{$\begin{array}{l}\text { All patients } \\
(n=269)\end{array}$} \\
\hline & $\mathbf{n}$ & $\%$ & $\mathbf{n}$ & $\%$ & $n$ & $\%$ & $\mathbf{n}$ & $\%$ \\
\hline \multicolumn{9}{|l|}{ ICU admission } \\
\hline Yes & 98 & 57 & 76 & 54 & 22 & 17 & 98 & 36 \\
\hline No & 54 & 43 & 66 & 46 & 102 & 80 & 168 & 62 \\
\hline Unknown & 0 & 0 & 0 & 0 & 3 & 2 & 3 & 1 \\
\hline \multicolumn{9}{|l|}{ Outcome $^{d}$} \\
\hline Recovered & 72 & 57 & 82 & 58 & 102 & 80 & 184 & 68 \\
\hline $\begin{array}{l}\text { Convalescing/ } \\
\text { stable }\end{array}$ & 53 & 42 & 58 & 41 & 22 & 17 & 80 & 30 \\
\hline Deteriorating & 1 & 1 & 1 & 1 & 0 & 0 & 1 & 0 \\
\hline Unknown & 1 & 1 & 1 & 1 & 3 & 2 & 4 & 1 \\
\hline
\end{tabular}

Abbreviations: ICU, intensive care unit; SARS-CoV-2, severe acute respiratory syndrome coronavirus 2

a Severe acute respiratory syndrome coronavirus 2

b Percentages are rounded to the nearest whole number. The sum of a category's percentages therefore may not add up to $100 \%$

One province or territory reported hospitalized cases only

${ }^{d}$ Patient outcomes were updated by provincial and territorial health authorities when possible. Data presented here were at the time of the most recent update

youth in December 2020 and early January 2021 (Figure 1). Although the incidence of COVID-19 declined from January 2021 to early March 2021, the number of MIS-C cases reported remained elevated for several reasons. First, MIS-C is a post-viral syndrome and literature reports suggest it typically manifests 2-6 weeks after SARS-CoV-2 infection (5-7). It is, therefore, expected that case numbers may remain high in the weeks following a high incidence of COVID-19. Second, COVID-19 case counts among children and youth in Canada were still high in the months of February and March 2021. As COVID-19 cases in children and youth have risen again in late March and April 2021, we can expect to see additional MIS-C cases reported following these periods.

Figure 1: Reported cases of multisystem inflammatory syndrome in children by epidemiological week of symptom onset compared with cases of COVID-19 in children and youth aged 0-19 years, Canada, March 11, 2020 to October 2, 2021( $\mathrm{N}=269)$

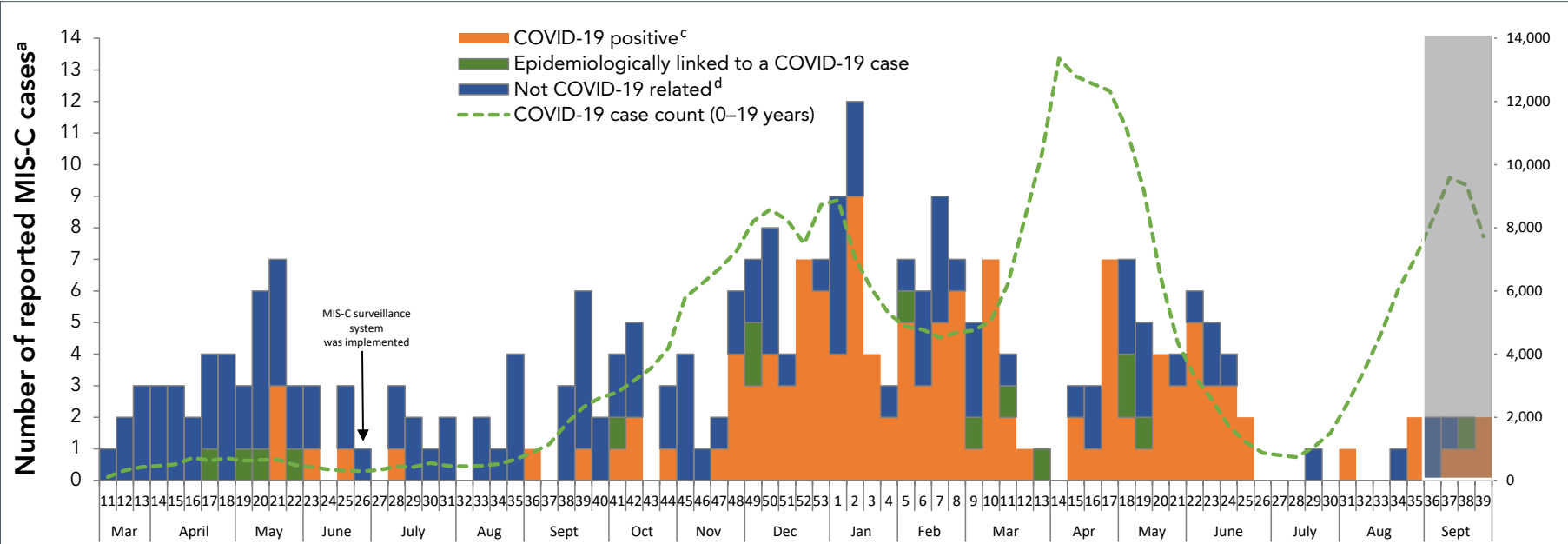

\section{Epidemiological week of symptom onset}

Abbreviations: COVID-19, coronavirus disease 2019; MIS-C, multisystem inflammatory syndrome in children

a Data source: MIS-C National reporting from provinces and territories

Data source: Coronavirus diseases 2019 national surveillance system

COVID-19 positive via RT-PCR, antigen test or serology

No known evidence of SARS-CoV-2 infection or exposure to a COVID-19 case

Note: The shaded area represents a period of time where it is expected that cases have occurred but have not yet been reported nationally 


\section{Strengths and limitations}

The data in this report are subject to several limitations. First, data are incomplete as not all provinces and territories participated in the national surveillance of MIS-C and one province only reported cases that were lab-confirmed. Second, case reporting may also be delayed due to limited capacity at provincial and territorial health authorities. Case counts for the most recent couple of months in particular should be interpreted with caution. Third, it is difficult to discern whether cases were infected with COVID-19 or not due to several factors: RT-PCR testing may be negative if completed too late in the course of infection; serology testing may not be available; there are inherent challenges in interpreting serology results; and patients may not know that they have been in contact with a case of COVID-19. For this reason, cases with no known evidence of SARS-CoV-2 infection or exposure to a COVID-19 case were included in the analysis; however, these cases may not be COVID-19-related and, therefore, not true cases of MIS-C. Due to similarities between the symptoms of MIS-C and Kawasaki disease and the difficulties in diagnosing these diseases, there may be misclassification of cases, especially the cases without a known COVID-19 link. More detailed laboratory testing data is needed to further differentiate between cases related and unrelated to COVID-19.

\section{Conclusion}

Cases of MIS-C in Canada are rare; however, when illness does occur it is severe, with nearly all cases requiring hospitalization and one third requiring admission to the intensive care unit. All children in Canada with MIS-C have recovered or are recovering, with no deaths reported. The time trend of MIS-C aligns with the time trend of the incidence of COVID-19 in children, with a two- to six-week lag. This pattern has been reported in other publications, supporting 1) the temporal association of MIS-C with COVID-19 and 2) the current understanding that MIS-C results from a delayed immunologic response to SARS-CoV-2 infection (7). In Canada, MIS-C is more likely to occur in males then females.

Although MIS-C is rare, it is serious, and it is not yet known why some children develop this syndrome and others do not. Furthermore, the long-term effects of MIS-C remain largely unknown. The most effective way to prevent cases of serious illness in children is to follow public health measures that prevent the spread of COVID-19, including physical distancing, wearing masks, hand hygiene, staying home when sick and getting vaccinated against COVID-19 when eligible. The Public Health Agency of Canada will continue to work with provincial and territorial partners to monitor cases of serious inflammatory illness in children and keep the public informed of the risk to children and youth.

\section{Authors' statement}

$\mathrm{ML}$ - Methodology, software, formal analysis, investigation, data curation, writing-original draft, writing-review and editing, visualization

MS - Conceptualization, writing-original draft, writing-review and editing

SGS - Conceptualization, writing-original draft, writing-review and editing

MA - Writing-original draft, writing-review and editing

LE - Writing-original draft, writing-review and editing

$\mathrm{SL}$ - Writing-original draft, writing-review and editing

ADC - Writing-original draft, writing-review and editing

YAL - Conceptualization, methodology, writing-original draft, writing-review and editing, project administration

\section{Competing interests}

None.

\section{Acknowledgements}

We would like to thank all provincial and territorial health authorities and Canadian Pediatric Surveillance Program collaborators for their contributions to multisystem inflammatory syndrome in children (MIS-C) surveillance in Canada. We would also like to thank Public Health Agency of Canada colleagues $\mathrm{T}$ Bennett in data validation, and R MacTavish and A Agarwal for managing the database and providing the update to this report.

\section{Funding}

None.

\section{References}

1. Centers for Disease Control and Prevention. CDC Health Alert Network. Multisystem Inflammatory Syndrome in Children (MIS-C) Associated with Coronavirus Disease 2019 (COVID-19). Atlanta, GA: CDC; 2020. https://emergency.cdc.gov/han/2020/han00432.asp

2. Word Health Organization. Multisystem inflammatory syndrome in children and adolescents temporally related to COVID-19. Geneva, CH: WHO; 2020.

https://www.who.int/news-room/commentaries/detail/ multisystem-inflammatory-syndrome-in-children-andadolescents-with-covid-19

3. Kucirka LM, Lauer SA, Laeyendecker O, Boon D, Lessler J. Variation in False-Negative Rate of Reverse Transcriptase Polymerase Chain Reaction-Based SARS-CoV-2 Tests by Time Since Exposure. Ann Intern Med 2020;173(4):262-7. DOI PubMed

4. Centers for Disease Control and Prevention. About Kawasaki Disease. Atlanta, GA: CDC; 2020 (accessed 2021-04-07). https://www.cdc.gov/kawasaki/about.html 
5. Feldstein LR, Rose EB, Horwitz SM, Collins JP,

Newhams MM, Son MB, Newburger JW, Kleinman LC, Heidemann SM, Martin AA, Singh AR, Li S, Tarquinio KM, Jaggi P, Oster ME, Zackai SP, Gillen J, Ratner AJ, Walsh RF, Fitzgerald JC, Keenaghan MA, Alharash H, Doymaz S, Clouser KN, Giuliano JS Jr, Gupta A, Parker RM, Maddux AB, Havalad V, Ramsingh S, Bukulmez $H$, Bradford TT, Smith LS, Tenforde MW, Carroll CL, Riggs BJ, Gertz SJ, Daube A, Lansell A, Coronado Munoz A, Hobbs CV, Marohn KL, Halasa NB, Patel MM, Randolph AG; Overcoming COVID-19 Investigators; CDC COVID-19 Response Team. Multisystem Inflammatory Syndrome in U.S. Children and Adolescents. N Engl J Med 2020;383(4):334-46. DOl PubMed

6. Dufort EM, Koumans EH, Chow EJ, Rosenthal EM, Muse A, Rowlands J, Barranco MA, Maxted AM, Rosenberg ES, Easton D, Udo T, Kumar J, Pulver W, Smith L, Hutton B, Blog D, Zucker H; New York State and Centers for Disease Control and Prevention Multisystem Inflammatory Syndrome in Children Investigation Team. Multisystem Inflammatory Syndrome in Children in New York State. N Engl J Med 2020;383(4):347-58. DOI PubMed
7. Belay ED, Abrams J, Oster ME, Giovanni J, Pierce T, Meng L, Prezzato E, Balachandran N, Openshaw JJ, Rosen HE, Kim M, Richardson G, Hand J, Tobin-D'Angelo M, Wilson S, Hartley A, Jones C, Kolsin J, Mohamed H, Colles Z, Hammett T, Patel P, Stierman B, Campbell AP, Godfred-Cato S. Trends in Geographic and Temporal Distribution of US Children With Multisystem Inflammatory Syndrome During the COVID-19 Pandemic. JAMA Pediatr 2021;175(8):837-45. DOI PubMed

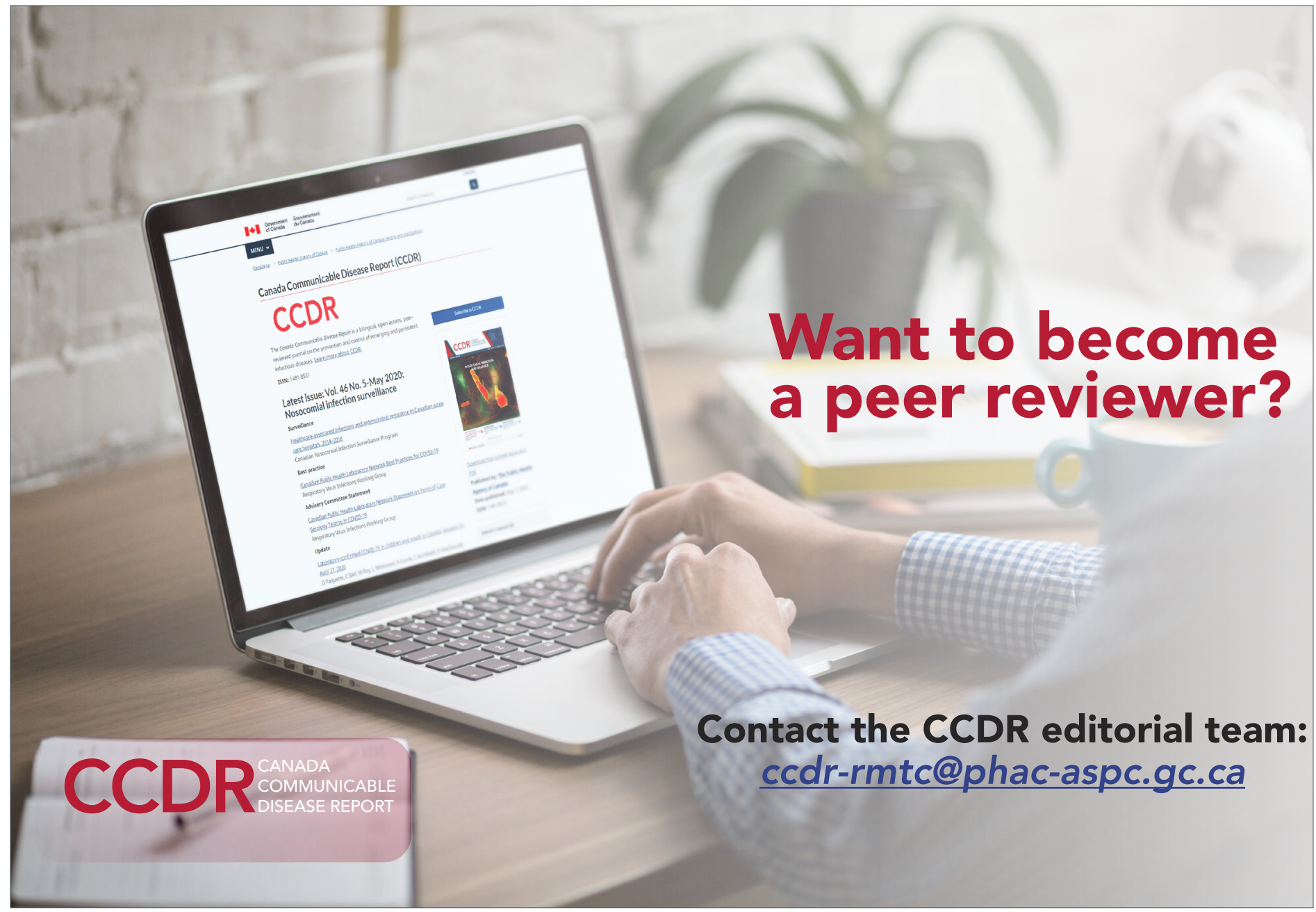

